\title{
Let me Entertain You - the Influence of Augmented Reality on Purchasing Intention in E-Commerce
}

\author{
Bettina Beurer-Züllig \\ Zurich University of Applied \\ Sciences \\ bettina.beurer-zuellig@zhaw.ch
}

\author{
Anna Victoria Rozumowski \\ Zurich University of Applied \\ Sciences \\ anna.rozumowski@zhaw.ch
}

\author{
Michael Klaas \\ Zurich University of Applied \\ Sciences \\ michael.klaas@zhaw.ch
}

\begin{abstract}
Augmented reality (AR) in e-commerce helps consumers to envision products in their respective surroundings, so fosters customer experience. Our online experiment with 302 probands explores the effect of AR on purchasing intention, taking into account motivational variables-perceived usefulness, entertainment and perceived ease of use (PEOU). Consumers viewing products in an ARenabled online shop rated perceived usefulness, entertainment and PEOU significantly higher than the control group viewing the non-AR-enabled online shop. Performing mediation analysis, we found that AR significantly influences purchase intention, which is mediated by perceived entertainment. Our findings add to the understanding of the interplay of the motivational variables perceived usefulness, entertainment and PEOU as well as the impact of $A R$ on customer decision making. From a managerial point of view, our findings suggest that in the current stage of the technology, AR is perceived as a playful add-on to online shopping, positively impacting purchase intention.
\end{abstract}

\section{Introduction}

"Augmented reality promises to be as influential to our society as smartphones." Tim Cook, CEO, Apple

In the wake of COVID-19, e-commerce numbers kept growing by a staggering $25 \%$ worldwide in 2020 , accounting for USD 360 billion net sales in the U.S. in 2019 [1]. Offline businesses have realized the evergrowing importance of online channels by integrating e-commerce platforms into their business models [24]. E-commerce retailers face the challenge of lacking tactile customer experience of their assortment [5]. Hence, consumers often struggle to envision how products might fit in their respective lives [6, 7]. This is especially true for non-commodity goods and bigger investments, as they require higher risks [8]. AR has the potential to close this gap by virtually integrating products in the consumers' context and real environment [7, 9-11] creating a more realistic product experience $[10,12]$. By adding further cues, AR adds to customer experience, facilitates consumer decisionmaking [13, 14], and has the potential to raise trust by diminishing perceived purchasing risk $[15,16]$. As virtual goods become more tangible by the application of AR, consumers more often decide to spare themselves the hassle of visiting brick-and-mortar stores and instead shop online [6]. Companies like L'Oréal, IKEA, Akzo Nobel and Nike are integrating AR to embed digital content in real-time into the physical surroundings of their customers [6] and enhance the online shopping experience $[5,9,17]$. According to Dacko [9], consumers value brands and retailers that offer AR technology more due to enhanced online shopping experience. Gartner Research [18] has deleted AR from the emerging technology hype cycle in 2020, as AR is rapidly approaching a mature state, and more AR apps are expected to go live in the near future.

Smink, et al. [10] give a comprehensive overview of AR studies. Up to date, most studies focus on technology acceptance aspects or AR media characteristics, neglecting AR's contribution to customer decision making [7, 16]. Fan, et al. [5] highlight that the focus on technology acceptance is ignoring AR's impact on consumer's product attitudes and purchase intentions. According to Smink, et al. [10], there is limited literature regarding the benefits of AR in online shopping so far, with the majority of research focusing on self-augmentation. Only few studies deal with AR applications that augment products in consumers' surroundings $[10,12]$. Makhitha and Ngobeni [15] state that further studies should investigate the risk-reduction effect of augmented reality in online shopping. Brengman, et al. 
[16] as well as Smink, et al. [10] show a positive influence of AR on purchase intention using student sample and recommend analyzing a more general population to find out whether results can be replicated. Based on these arguments, this paper aims to answer the following research questions:

RQ1: Does AR influence consumer trust and risk perception as well as purchase intention?

RQ2: Do motivational variables mediate the influence of AR on purchase intention?

\section{Theoretical Context}

In researching the effects of $\mathrm{AR}$ on trust, risk perception and purchase intention, it is important to understand customers' evaluation of the technology regarding usefulness, ease of use as well as entertainment value.

\subsection{E-Commerce and AR}

$\mathrm{AR}$ is blurring the boundaries between online and offline channels, creating a holistic customer experience [6, 7]. AR is defined as systems that integrate virtual information into the physical environment of users, making information experienceable in the desired environment $[11,16,19$ 23]. According to Ye, et al. [20], AR is characterized by three basic functions: a combination of real and virtual worlds, real-time interaction and precise 3D registration of virtual and real objects. In contrast to regular mobile applications, mobile-enabled AR merges virtual images or information with the real environment [16]. Mobile devices are popular for online shopping [24], being the most frequently used devices for online shopping in the U.S. [1]. Consumers have their smartphones with them wherever they are, and pre-stored user information accelerates and fosters ease of shopping [25]. Smartphones are able to track location, recognize context, and check website visitors [24], enabling improved customer experience and individual offers. AR further fosters a strong interactive customer experience [20, 23], making online shopping more enjoyable [9]. AR features support consumers in the decision-making process, choosing products that suit their needs more precisely [5]. By simplifying product information processing AR reduces consumers' cognitive load, making purchasing decisions more comfortable and hence increasing positive attitude towards the product [5].

According to Tran, et al. [26], consumers prefer product information via AR applications over text and $2 \mathrm{D}$ pictures in online shops. $\mathrm{AR}$ is increasing consumers information volume and convenience, having the potential to decrease risk in buying decisions $[6,8,19]$ and to eliminate dissatisfaction due to unmet expectations [6], as the additional information is able to compensate for the lack of physical cues. AR shopping environments foster trust in the competencies of an enterprise [27]. Another advantage of AR is the notion of psychological possession of a product, which is suggested by product experience in the consumers surroundings [16]. Furthermore, AR is especially suitable for hedonistic consumers seeking diversion and entertainment while shopping online $[28,29]$ as new customer experiences can be created.

\subsection{Trust}

Trust is the cornerstone of business: practically all interactions require a degree of trust. This is even more true for e-commerce, which involves higher purchasing risks and uncertainties for consumers [30, 31]. E-commerce retailers need to convey a sense of dependability, reliability and security to make up for the lack of personal contact and tangibility of products $[30,32]$. Trust is often related to subjective guaranties that an online retailer will fulfill its obligations and act in favor of its client [30]. Past customer experience with a retailer is a basis for trust [33, 34]. Whereas trust positively impacts purchase intention [35-37] and purchasing decisions $[36,38]$, the lack of trust is the most prevalent barrier to online purchasing [39, 40].

Online trust is defined by three dimensions: ability, integrity, and benevolence $[32,41]$. Ability reflects a company's competence to fulfill its promises, whereas integrity relates to reliable, honest and consistent business behavior [39]. Benevolence characterizes a company's willingness to put benefit of the customer first. Pavlou [31] states that trust reduces the need for control in e-commerce settings, increasing the perceived ease of use (PEOU). Trust is an important determinant of expected utility of an online shop, customer relationship quality $[33,34,42]$ and hence of purchase intention $[30,31,40,41]$. Ke, et al. [4] emphasize the importance of trust for online transactions as online buyer-seller relationships involve more risk elements. Trust and risk perception are two intertwined concepts: in an online setting consumers weigh perceived risk against trust in the eretailer when making purchasing decisions [43]. Trust can effectively reduce perceived risk in online retailing $[31,35,43]$.

\subsection{Risk Perception}

Perceived risk influences consumer behavior and is hence an important element in $\mathrm{B} 2 \mathrm{C}$ e-commerce 
[31]. Risk perception is related to fear of loss or anxiety that interactions do not turn out the desired way [44]. Online shoppers perceive four kinds of risk: product performance risk, financial risk, time/convenience risk [45, 46], and psychological risk [47]. The bigger the perceived risk, the less likely a customer is to purchase a good [48] and perform a business transaction [44]. Though online shopping belongs to the everyday life of most consumers, risk perception in online shopping is still higher than in brick-and-mortar retail [49, 50]. Consumers are striving to reduce risk and maximize utility by obtaining additional information before purchasing $[48,51]$. Consumers perceiving decreased risk spend more online [46]. Decreased risk perception also leads to higher frequency of searches with intention to buy, higher frequency of online purchases [46, 49] and increased online loyalty [49]. AR poses a strategy to deliver additional information and reduce risk perception [52]. In particular, product performance risk can be potentially reduced by the additional information provided by AR $[45,53]$.

\subsection{Technology Acceptance Model (TAM)}

The relation between consumer perception, like trust and risk in online shopping, and TAM has gained notable attention in the literature [32, 54-56]. There are various extensions to the TAM framework incorporating additional constructs to better capture user experience and behavior [17]. Kim and Forsythe [53] extended TAM by introducing SE-TAM, stating that the sensory enabling technology adoption process is driven by hedonic (perceived entertainment, PE) and utilitarian (perceived usefulness, PU) shopper motivations as well as PEOU. Rese, et al. [17] give a comprehensive overview of studies on the acceptance of AR applications in retailing. While literature on AR focuses on technology acceptance aspects, there is scarce research on its impact on customer decision making [7]. Alves and Luís Reis [57] found that PEOU of an AR application increases purchase attractiveness. Chong [58] puts forth that consumers are more likely to engage in $\mathrm{m}$-commerce activities, if they perceive them as enjoyable.

\subsection{Purchase Intention}

Online purchase intention can be described as a consumer's intention to perform online purchasing behavior [59]. Purchase intention is a direct indicator for actual buying behavior [60]. Customer attitude, which is influenced by reputation, size, and recommendations by third parties, impacts purchase intention [32, 35]. Furthermore, ease of use as well as innovative website design positively affect purchase intention [30, 31, 39]. According to Patanasiri and Krairit [48], the integration of interactive functions enhances consumers' perceived value and utility of ecommerce websites, leading to increased purchase intention. Previous studies found evidence that AR has a positive effect on purchase intention [10, 12, 52, 61].

We would therefore like to contribute to the current literature by conducting further research presented in this paper with a focus on the impact of AR on customer decision making, taking into account trust and risk perception (RQ1) as well as SE-TAM variables perceived usefulness, entertainment and PEOU (RQ2).

\section{Methods}

To elicit on the influence of AR on customer decision making, we conducted an online experiment with a sample of 420 probands.

\subsection{Sample}

The survey was shared using a Swiss panel provider. Of the 420 probands filling out the questionnaire, 317 completed it. After screening the data, we deleted 15 outliers, which leads to a final $\mathrm{n}=302$. The sample is split equally between both scenarios, with 152 probands belonging to the control group (online shop without AR) and 150 to the experimental group (online shop with AR). We have set a quota for the gender (50/50); hence the sample represents male (50\%) and female (49.7\%) alike. One person chose to not answer the question about gender. On average, the respondents are 40.49 years old. More than $47 \%$ of the respondents have completed a vocational apprenticeship, and more than $18 \%$ of the respondents hold a university degree at bachelor, master, or PhD level. All respondents have shopped online in the past 6 months, as this was defined as a prerequisite for participation in the study.

\subsection{Stimulus Material}

In 2020, furniture and appliances have seen an additional growth of $7.6 \%$ in e-commerce revenue in the U.S. [1]. AR technologies are especially suitable for products requiring visual cues and are particularly interesting for furniture or home decoration [16]. Hence, products chosen for stimulus material belong to the range of home styling products, namely indoor plants, since it is particularly relevant to assessing home décor in the real environment. 
We employed screen recordings (videos of about 1 minute) of the online plant shop as stimulus material. The selected indoor plant "Monstera XL" represents a high-priced high-involvement product, which could easily be integrated in the living rooms of probands. Rese, et al. [17] suggest implementing a control group with an interactive non-augmented app. The control group was, therefore, presented with a screen recording of the online shop without AR. Thus, information about the plant as well as pictures from the online plant provider were shown to the subjects. The experimental group also saw a screen recording taken from the same online plant shop showing the same "Monstera XL" but adding the AR solution showing the product in a customer's surrounding.

\subsection{Measures}

We employed existing validated scales, which were adapted to the survey setting to measure the underlying constructs. We measured online trust via an eleven-item scale from $\mathrm{Ke}$, et al. [4]. To measure risk perception, we employed scales from Jarvenpaa, et al. [35] for overall web-shopping risk attitudes (three items) and from Forsythe, et al. [45] for perceived product risk (six items). To elicit the motivational variables perceived usefulness, PEOU and entertainment value of AR we utilized the SETAM scale from Kim and Forsythe [53]. Purchase intention was captured via the three-item scale from Kim [54]. We included the following control variables: past online shopping experience [31, 50], actual transaction behavior [31] and brand recognition [39].

We choose between-subjects-design with each proband being randomly assigned to one scenario. The structured questionnaire prompted the following subjects: trust, risk perception, perceived usefulness, PEOU and entertainment value of $\mathrm{AR}$, as well as purchase intention. Effects were measured using statements rated via seven-point Likert scales, with the endpoints "do not agree at all" (=1) and "fully agree" $(=7)$. The questionnaire was pretested with experts, which led to a reformulation of questions for improved fit. To test the success of the manipulation, participants were asked to answer a question prompting the viewed product presentation (screen recording of online shop with vs without AR).

\section{Data Analysis}

This section describes the statistical tests conducted on the data sample. To elicit whether online trust, purchase intention, risk, and the sensory enabling technology acceptance perceptions differ amongst the control and the experimental group, ANOVAs were performed. To determine the influence of the SE-TAM constructs on online trust and purchase intention, we conducted a mediation analysis.

\subsection{Descriptive Statistics}

Our data show that $49.7 \%$ of the participants shop online several times a year. $44.4 \%$ shop online several times a month and another $6 \%$, several times a week. $24.5 \%$ of the participants have already bought plants online, whereas more than $66 \%$ bought $1-2$ plants online in the past 3 years.

We integrated a manipulation check to the survey, and 230 probands were able to correctly indicate whether they saw the online shop without or the online shop including the AR solution. According to Hoewe [62], if a manipulation check fails in an experimental setting, it may be that the instructions were not clear to the subjects. However, a failed manipulation check does not mean that all subjects who answered incorrectly must be deleted from the sample [62].

Before we surveyed the motivational variables of SE-TAM questions, we integrated an explanation of AR solutions in e-commerce. After the explanation, we asked whether the participants already used AR when shopping online. $77.5 \%$ indicated that they never used AR before, and another $8.6 \%$ were unsure. $13.9 \%$ have already used AR when shopping online.

\subsection{Factor Analysis}

Based on the literature review, we employed 34 items to measure online trust, purchase intention, product risk and SE-TAM constructs perceived usefulness, entertainment, and PEOU in a retail environment. A Kaiser-Meyer-Olkin (KMO) measure of sampling adequacy was computed to explore whether factor analysis was suitable. We obtained a KMO value of 0.92 for the 34 items, which is considered excellent [63]. We conducted explorative factor analysis (EFA) by using the principal component analysis method with Varimax rotation and Kaiser normalization.

According to Hair et al. [64], variables with factor loadings above 0.5 are very significant. Moreover, cross-loadings \pm .2 described by Hair, et al. [65] and Stamper and Masterson [66] should be deleted. Therefore, we deleted 1 variable, and the final factor analysis included 33 variables that load on eight factors. The final EFA shows a KMO value of 0.922 and is highly significant. The eight factors explain 
$77.666 \%$ of the variance. We identified eight different constructs, displayed in Table 1.

\subsection{Construct Validity}

To measure the reliability of the instrument, Cronbach's alpha coefficient was used. Table 1 gives the computed values for the constructs. Eckstein [67] proposes that an alpha of 0.6 or higher is acceptable; therefore, we conclude that the constructs are reliable.

Table 1. Reliability coefficients

\begin{tabular}{lr}
\hline \multicolumn{1}{c}{ Measure } & Alpha \\
\hline Total 33 Items & 0.894 \\
Online Trust (11 items) & 0.968 \\
Purchase Intention (3 items) & 0.865 \\
Product Risk (Product) (4 items) & 0.746 \\
Product Risk (Delivery) (2 items) & 0.698 \\
Online Risk Attitude (2 items) & 0.715 \\
Usefulness (4 items) & 0.937 \\
PEOU (3 items) & 0.857 \\
Entertainment (4 items) & 0.939 \\
\hline
\end{tabular}

\subsection{ANOVA}

To test whether the two groups differ significantly in their perceptions, an one-way analysis of variance is calculated $[68,69]$. The descriptive statistics as well as the results from the ANOVA are described hereafter. The experimental group, who saw the AR solution, indicated slightly less online trust towards the online plant shop than the control group, who saw the online shop only. These differences are not significant $\left(\mathrm{F}(3,300)=, 000, \mathrm{p}=.986, \mathrm{M}_{\text {control }}=\right.$ 5,1077 , and $\mathrm{M}_{\text {experimental }}=5.1055$ ). The AR integration leads to slightly higher purchase intentions. These differences are not significant $(\mathrm{F}(3,300)=1,594, \mathrm{p}=$ $.208, \mathrm{M}_{\text {control }}=5,1689$, and $\left.\mathrm{M}_{\text {experimental }}=5,3756\right)$. The risk perceptions towards the product are slightly higher in the control group. Thus, the AR integration leads to risk reduction, however, these differences are not significant $\left(\mathrm{F}(3,300)=, 159, \mathrm{p}=.690, \mathrm{M}_{\text {control }}=\right.$ 4,6316 , and $\left.\mathrm{M}_{\text {experimental }}=4,5767\right)$. The risk perception towards online shopping is lower when people saw the AR integration. These differences are not significant $\left(\mathrm{F}(3,300)=2,173, \mathrm{p}=.141, \mathrm{M}_{\text {control }}=4,1842\right.$, and $\left.\mathrm{M}_{\text {experimental }}=3,9533\right)$. The risk perception towards delivery are not significant $(\mathrm{F}(3,300)=, 037, \mathrm{p}=.848$, $\mathrm{M}_{\text {control }}=4,2434$, and $\left.\mathrm{M}_{\text {experimental }}=4,2767\right)$. The control and the experimental group differ significantly along the SE-TAM scales. The participants who saw the plant inclusive the $A R$ integration rated the perceived usefulness significantly higher than the control group $\left(\mathrm{F}(3,300)=6,769, \mathrm{p}=.010, \mathrm{M}_{\text {control }}=\right.$ 4,5658 , and $\left.\mathrm{M}_{\text {experimental }}=4,9633\right)$. The PEOU is significantly higher in the experimental group $\left(\mathrm{F}(3,300)=9,017, \mathrm{p}=.003, \mathrm{M}_{\text {control }}=4,8575\right.$, and $\left.\mathrm{M}_{\text {experimental }}=5,2689\right)$. The same applies for the perceived entertainment $(\mathrm{F}(3,300)=7,721, \mathrm{p}=.006$, $\mathrm{M}_{\text {control }}=4,9507$, and $\left.\mathrm{M}_{\text {experimental }}=5,3567\right)$.

We asked the participants whether they already bought plants online. 74 participants indicated that they have already ordered plants online. At a 0.1significance level, people who have already bought plants online rate online trust more than people who $\operatorname{did} \operatorname{not}\left(\mathrm{F}(1,300)=2,850, \mathrm{p}=.092, \mathrm{M}_{\mathrm{yes}}=5,2899\right.$, and $\left.\mathrm{M}_{\mathrm{no}}=5,0470\right)$. Further significant differences are found in the risk perceptions towards the product $\left(\mathrm{F}(1,300)=2,733, \mathrm{p}=.099, \mathrm{M}_{\mathrm{yes}}=4,4054\right.$, and $\mathrm{M}_{\mathrm{no}}=$ 4,6689). Thus, people who have already bought plants online rate the product risk significantly lower.

The following analyses consider only the experimental group, thus, people who saw the AR integration in the online shop $(\mathrm{n}=150)$. No significant differences in the perceptions were found in gender and the educational level in the experimental group.

Further ANOVAs are calculated to detect whether there are differences between the age groups. Therefore, we build the following age groups: 17 to 25 $(n=31), 26$ to $35(n=39), 36$ to $45(n=31), 46$ to 55 $(n=19), 56$ to $65(n=14), 66$ to $75(n=14)$, and 76 to 85 $(n=2)$. Significant differences within the age group are found for the product risk perception, usefulness, and entertainment. At the .10-significance level, there are significant differences for the product risk perception $\left(\mathrm{F}(6,143)=1.939, \mathrm{p}=.078, \mathrm{M}_{17-25}=4,3871, \mathrm{M}_{26-35}=\right.$ 4,5962, $\mathrm{M}_{36-45}=4,2581, \mathrm{M}_{46-55}=5,3421, \mathrm{M}_{56-65}=$ 4,3571, $\mathrm{M}_{66-75}=4,7679$, and $\left.\mathrm{M}_{76-85}=5,0000\right)$. The participants between 46 and 55 years, attribute the greatest usefulness to the AR solution in the online shop $\left(\mathrm{F}(6,143)=2,383, \mathrm{p}=.032, \mathrm{M}_{17-25}=5,1532, \mathrm{M}_{26}\right.$ ${ }_{35}=5,1154, \mathrm{M}_{36-45}=4,9919, \mathrm{M}_{46-55}=5,3289, \mathrm{M}_{56-65}=$ $3,8393, \mathrm{M}_{66-75}=4,6964$, and $\mathrm{M}_{76-85}=4,8750$ ). The youngest age group rated the AR integration the most entertaining. These differences in the perceived entertainment are significant $(\mathrm{F}(6,143)=2,255, \mathrm{p}=$ $.041, \mathrm{M}_{17-25}=5,6290, \mathrm{M}_{26-35}=, 5,5833, \mathrm{M}_{36-45}=$, $5,4113, \mathrm{M}_{46-55}=, 5,4342, \mathrm{M}_{56-65}=, 4,4286, \mathrm{M}_{66-75}=$, and 4,8393, $\left.\mathrm{M}_{76-85}=5,2500\right)$.

\subsection{Mediation Analysis}

To test the role of the motivational SE-TAM variables usefulness, PEOU and entertainment on purchase intention, we ran a mediation analysis including two parallel mediators (M1, M2) and a third mediator (M3) using PROCESS (Model 80, Bootstrap 5'000) [70]. Online trust served as independent 
variable, usefulness, PEOU and entertainment (SETAM) as mediators, and purchase intention as the dependent variable, as displayed in Table 2.

Table 2. Mediation Analysis

\begin{tabular}{lrrrc}
\hline & & Coeff. & SE & p \\
\hline M1: Usefulness & $\mathrm{b}_{1}$ & .5822 & .0707 & .0000 \\
M2: PEOU & $\mathrm{b}_{2}$ & .4748 & .0755 & .0000 \\
M3: Entertainment & $\mathrm{b}_{3}$ & .1957 & .0439 & .0000 \\
& $\mathrm{~b}_{4}$ & .4677 & .0625 & .0000 \\
& $\mathrm{~b}_{5}$ & .3081 & .0646 & .0000 \\
Y: Purchase & $\mathrm{b}_{6}$ & .1163 & .0983 & .2376 \\
Intention & & & & \\
& $\mathrm{b}_{7}$ & -.0163 & .0959 & .8650 \\
& $\mathrm{~b}_{8}$ & -.0433 & .0905 & .6331 \\
& $\mathrm{~b}_{9}$ & .3371 & .1018 & .0010 \\
\hline
\end{tabular}

Online Trust emerged as a positive and significant predictor of Usefulness $(\mathrm{b} 1=.5822, \mathrm{p}<.001)$. The Rsquare $=.2195$ is indicating that Online Trust accounted for $21.95 \%$ of the variation. Online Trust emerges as a positive and significant predictor of PEOU (b2 $=.4748, \mathrm{p}<.001$ ). The R-square $=.1802$ is indicating that Online Trust accounted for $18.02 \%$ of the variation. When Entertainment is defined as the outcome variable, $64.39 \%$ of the variation is explained, and the model is highly significant $(\mathrm{p}<.001)$. Online Trust $(\mathrm{b} 3=.1957, \quad \mathrm{p}<.001)$, Usefulness (b4=.4677, $\mathrm{p}<.001)$, and PEOU (b5 $=.3081$, predictors of Purchase Intention. Entertainment (b9=.3371, $\mathrm{p}=.0010)$ is a positive and significant predictor of Purchase Intention.

The specific indirect effect [Ind1] of Online Trust on Purchase Intention via Usefulness (M1) is -.0095; bootstrap $95 \% \mathrm{CI}=(-.1154, .1021)$. This indirect effect is not significant. Furthermore, the specific indirect effect [Ind2] of Online Trust on Purchase Intention via PEOU (M2) is -.0205 ; bootstrap $95 \% \mathrm{CI}=(-.1032$, .0696). This indirect effect is not significant. The indirect effect [Ind3] of Online Trust on Purchase Intention via Entertainment (M3) is .0660; bootstrap $95 \% \mathrm{CI}=(.0226, .1178)$. This indirect effect is significant.

The specific indirect effect [Ind4] of Online Trust on Purchase Intention via the sequence of mediators, Usefulness (M1) and Entertainment (M3), is .0918; bootstrap $95 \% \mathrm{CI}=(.0340, .1589)$. This indirect effect is statistically significant. Moreover, the specific indirect effect [Ind5] of Online Trust on Purchase Intention via the sequence of mediators, PEOU (M2) and Entertainment (M3) are .0493; bootstrap 95\% $\mathrm{CI}=(.0159, .0982)$. This indirect effect is statistically significant.

\section{Findings}

Our data show that consumers rate web-shops that are AR-enabled significantly higher regarding the

Figure 1. Mediation Analysis

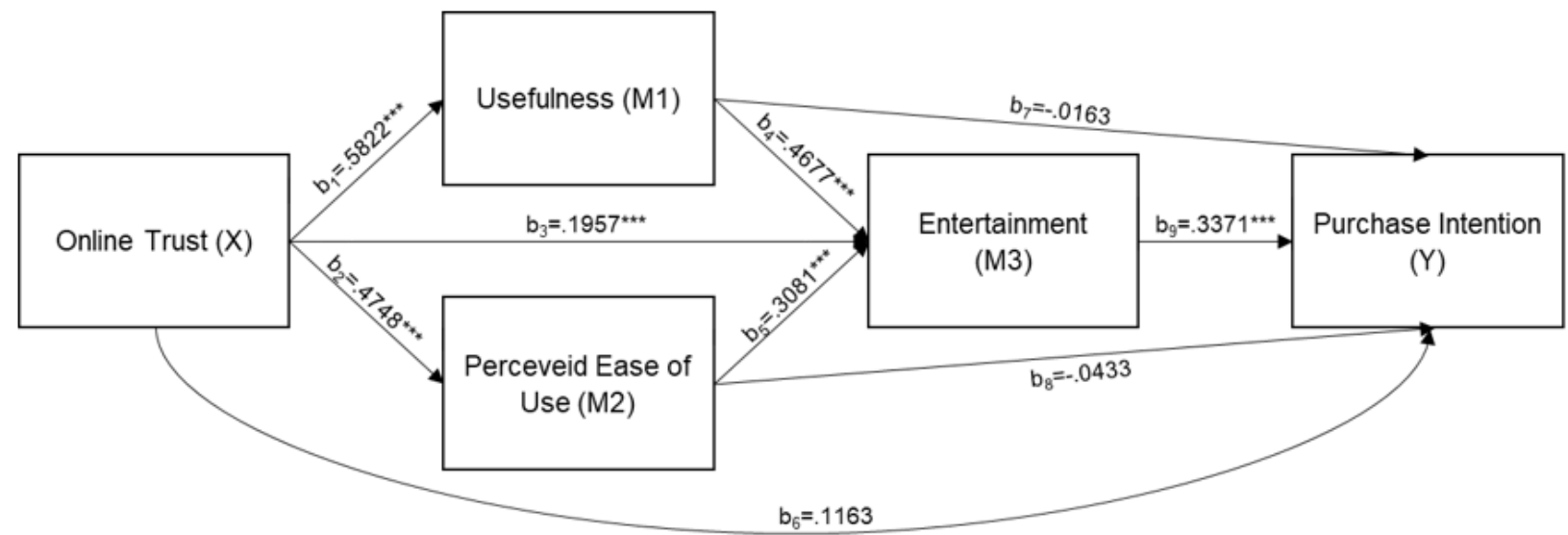

$\mathrm{p}<.001)$ are positive and significant predictors of Entertainment. For the path leading to Purchase Intention, the predictors (X, M1, M2, and M3) accounted for significant variation in Purchase Intention: R-square $=.1042 ; \mathrm{F}(4,297)=6.0137, \mathrm{p}=.001$. Online Trust is a positive and non-significant predictor of Purchase Intention ( $\mathrm{b} 6=.1163, \mathrm{p}=.2376$ ) in the model. Usefulness (b7=.-.0163, $\mathrm{p}=.8650$ ) and PEOU (b8 $=-.0433, \mathrm{p}=6331)$ are negative and non-significant motivational SE-TAM variables perceived usefulness, entertainment and PEOU. These findings are in line with Dacko [9], stating that AR increases the entertainment value of shopping. Furthermore, the experimental group displayed higher mean values for purchase intention and lower values for product risk, though not on a significant level. The risk reduction effect of AR as put forth by Makhitha and Ngobeni [15] could not be proven statistically significant in this 
study. Also the positive effect of AR on purchase intention as reported by Smink, et al. [10], Hilken, et al. [52] and Verhagen, et al. [61] could not be proven statistically significant in this study. Taking into account the influence of age, we found that the youngest cohort (17-25 years) rate AR as most enjoyable. This is consistent with the findings of Chong [58] stating that younger age groups are more likely to use m-commerce for entertainment.

Mediation analysis [70] reveals that perceived entertainment is a predictor of purchase intention. According to $\mathrm{Ha}$ and Stoel [71], the relationship between the three behavioral beliefs of perceived usefulness, entertainment and PEOU is unclear. This study finds that PEOU and perceived usefulness are positive and significant predictors of entertainment (compare Figure 1). Online trust significantly influences perceived usefulness, entertainment and PEOU, reaffirming trust as an important determinant of online shopping utility [33, 34, 42].

\section{Implications and Conclusion}

The objective of this study was to elicit the influence of AR on trust and purchase intention including the motivational variables perceived usefulness, entertainment and PEOU of SE-TAM. We found significant differences for the motivational variables between participants viewing products in online shopping settings with and without AR. Our study reaffirms that $\mathrm{AR}$ adds to the entertainment value of online shopping [9].

This study contributes to academic literature by expanding on the relationship between the three motivational variables of perceived usefulness, entertainment and PEOU with perceived usefulness and PEOU being significant predictors of entertainment. As hypothesized by Kim and Forsythe [53] the entertainment aspect of sensory-enabled technologies like AR have the potential to increase sales by influencing purchasing intention. As requested by Hilken, et al. [52] our study adds to the understanding of the influence of AR on customer decision making, showing a significant positive influence of perceived entertainment of AR apps on purchase intention.

Our study highlights the importance for e-retailers to integrate AR solutions in their web-shops to enhance shopping experience, driving purchase intention. With PEOU predicting entertainment, eretailers should carefully assess the ease of use of the implemented AR solution. As consumers over time grow more familiar with AR, we expect the playful aspect to wear off and usefulness take on greater importance.

\section{Limitations}

Our study is based on single-case data; therefore, further research is needed to verify and check the generalizability of the results found in this research. The design of the stimulus material could possibly affect trust and risk perception as well as perceived entertainment, usability and PEOU. Both Kim and Forsythe [53] and Rese, et al. [17] point out that the importance of the motivation variables perceived usefulness, entertainment, and PEOU vary for different kind of AR/VR apps. Future research should investigate the behavioral outcomes of AR-enabled online shops over time, as they are dependent on the time of usage [72] and familiarity.

\section{References}

[1] Statista, "eCommerce in the U.S. 2020," in "ecommerceDB Country Reports," did-70002-1, 2021.

[2] T. Escobar-Rodríguez and R. BonsónFernández, "Analysing online purchase intention in Spain: fashion e-commerce," Information Systems and e-Business Management, vol. 15, no. 3, pp. 599-622, 2017/08/01 2017, doi: 10.1007/s10257-016-0319-6.

[3] M. Arce-Urriza, J. Cebollada, and M. F. Tarira, "The effect of price promotions on consumer shopping behavior across online and offline channels: differences between frequent and non-frequent shoppers," Information Systems and e-Business Management, vol. 15, no. 1, pp. 69-87, 2017.

[4] D. Ke, A. Chen, and C. Su, "Online trustbuilding mechanisms for existing brands: the moderating role of the e-business platform certification system," Electronic Commerce Research, vol. 16, no. 2, pp. 189-216, 2016/06/01 2016, doi: 10.1007/s10660-016-9217-8.

[5] X. Fan, Z. Chai, N. Deng, and X. Dong, "Adoption of augmented reality in online retailing and consumers' product attitude: A cognitive perspective," Journal of Retailing and Consumer Services, vol. 53, p. 101986, 2020/03/01/ 2020, doi: 10.1016/j.jretconser.2019.101986.

[6] D. Mahr, D. I. Keeling, J. Heller, T. Hilken, M. Chylinski, and K. de Ruyter, "Making omnichannel an augmented reality: the current and future state of the art," Journal of Research in Interactive Marketing, vol. 12, no. 4, pp. 509-523, 2018, doi: 10.1108/JRIM-01-2018-0023.

[7] T. Hilken, J. Heller, M. Chylinski, D. I. Keeling, D. Mahr, and K. de Ruyter, "Making omnichannel an augmented reality: the current and 
future state of the art," Journal of Research in Interactive Marketing, 2018.

[8] F. Baytar, T.-1. D. Chung, and E. Shin, "Can Augmented Reality Help E-shoppers Make Informed Purchases on Apparel Fit, Size, and Product Performance?," in International Textile and Apparel Association Annual Conference Proceedings, 2016, vol. 73, no. 1: Iowa State University Digital Press.

[9] S. G. Dacko, "Enabling smart retail settings via mobile augmented reality shopping apps," Technological Forecasting and Social Change, vol. 124, pp. 243-256, 2017/11/01/ 2017, doi: 10.1016/j.techfore.2016.09.032.

[10] A. R. Smink, E. A. van Reijmersdal, G. van Noort, and P. C. Neijens, "Shopping in augmented reality: The effects of spatial presence, personalization and intrusiveness on app and brand responses," Journal of Business Research, vol. 118, pp. 474-485, 2020/09/01/ 2020, doi: 10.1016/j.jbusres.2020.07.018.

[11] J. Scholz and A. N. Smith, "Augmented reality: Designing immersive experiences that maximize consumer engagement," Business Horizons, vol. 59, no. 2, pp. 149-161, 2016/03/01/ 2016, doi: 10.1016/j.bushor.2015.10.003.

[12] H. Park and S. Kim, "Do Augmented and Virtual Reality Technologies Increase Consumers' Purchase Intentions? The Role of Cognitive Elaboration and Shopping Goals," Clothing and Textiles Research Journal, vol. 0, no. 0, p. 0887302X21994287, 2021, doi: $10.1177 / 0887302 \times 21994287$.

[13] N. Kshetri, "5G in E-Commerce Activities," IT Prof., vol. 20, no. 4, pp. 73-77, 2018.

[14] A. Javornik, "Augmented reality: Research agenda for studying the impact of its media characteristics on consumer behaviour," Journal of Retailing and Consumer Services, vol. 30, pp. 252261, 2016/05/01/2016, doi: 10.1016/j.jretconser.2016.02.004.

[15] K. M. Makhitha and K. Ngobeni, "The influence of demographic factors on perceived risks affecting attitude towards online shopping," 2021, online shopping; consumer behaviour; demographic factors; perceived risk; attitude; privacy and security risk; product risk; delivery risk. vol. 23, no. 1, 202102-22 2021, doi: 10.4102/sajim.v23i1.1283.

[16] M. Brengman, K. Willems, and H. Van Kerrebroeck, "Can't touch this: the impact of augmented reality versus touch and non-touch interfaces on perceived ownership," Virtual Reality, vol. 23, no. 3, pp. 269-280, 2019/09/01 2019, doi: 10.1007/s10055-018-0335-6.

[17] A. Rese, D. Baier, A. Geyer-Schulz, and S. Schreiber, "How augmented reality apps are accepted by consumers: A comparative analysis using scales and opinions," Technological Forecasting and Social Change, vol. 124, pp. 306-319, 2017/11/01/2017, doi: 10.1016/j.techfore.2016.10.010.

[18] G. Research, "Hype Cycle for Emerging Technologies 2020," July 2020 2020. [Online]. Available:

https://www.gartner.com/smarterwithgartner/5trends-drive-the-gartner-hype-cycle-for-emergingtechnologies-2020/

[19] S. O'Mahony, "A proposed model for the approach to augmented reality deployment in marketing communications," Procedia-Social and Behavioral Sciences, vol. 175, pp. 227-235, 2015.

[20] H. Ye, R. Shi, S. Li, and D. Li, "Research on the Application Process of Mobile Augmented Reality in Printed Product," in China Academic Conference on Printing \& Packaging and Media Technology, 2016: Springer, pp. 357-365.

[21] A. Welivita, N. Nimalsiri, R. Wickramasinghe, U. Pathirana, and C. Gamage, "Virtual Product Try-On Solution for E-Commerce Using Mobile Augmented Reality," Cham, 2017: Springer International Publishing, in Augmented Reality, Virtual Reality, and Computer Graphics, pp. 438-447.

[22] K. N. Kumar, S. Chandra, S. Bharati, and S. Manava, "Factors influencing adoption of augmented reality technology for e-commerce," in Pacific Asia Conference on Information Systems (PACIS), 2016: Association For Information System.

[23] P. Q. Brito, J. Stoyanova, and A. Coelho, "Augmented reality versus conventional interface: Is there any difference in effectiveness?," Multimedia Tools and Applications, vol. 77, no. 6, pp. 7487-7516, 2018/03/01 2018, doi: 10.1007/s11042-017-4658-1.

[24] Y. Cai and B. J. Cude, "Online Shopping," in Handbook of Consumer Finance Research, J. J. Xiao Ed. Cham: Springer International Publishing, 2016, pp. 339-355.

[25] P. Papadopoulou and J.-E. Pelet, "Trust and Privacy in the Shift from E-Commerce to MCommerce: A Comparative Approach," Berlin, Heidelberg, 2013: Springer Berlin Heidelberg, in Collaborative, Trusted and Privacy-Aware e/mServices, pp. 50-60.

[26] M. Q. Tran, S. Minocha, D. Roberts, A. Laing, and D. Langdridge, "A Means-End Analysis of Consumers' Perceptions of Virtual World Affordances for E-commerce," Berlin, Heidelberg, 2011: Springer Berlin Heidelberg, in Human-Computer Interaction INTERACT 2011, pp. 362-379.

[27] P. Papadopoulou, "Applying virtual reality for trust-building e-commerce environments," Virtual Reality, vol. 11, no. 2-3, pp. 107-127, 2007. 
[28] A. Bilgihan, "Gen Y customer loyalty in online shopping: An integrated model of trust, user experience and branding," Computers in Human Behavior, vol. 61, pp. 103-113, 2016/08/01/ 2016, doi: 10.1016/j.chb.2016.03.014.

[29] J. Karać and M. Stabauer, "Gamification in E-Commerce," Cham, 2017: Springer International Publishing, in HCI in Business, Government and Organizations. Supporting Business, pp. 41-54.

[30] M.-Y. Chen and C.-I. Teng, "A comprehensive model of the effects of online store image on purchase intention in an e-commerce environment," Electronic Commerce Research, vol. 13, no. 1, pp. 1-23, 2013.

[31] P. A. Pavlou, "Consumer Acceptance of Electronic Commerce: Integrating Trust and Risk with the Technology Acceptance Model," International Journal of Electronic Commerce, vol. 7, no. 3, pp. 101-134, 2003/04/01 2003, doi: 10.1080/10864415.2003.11044275.

[32] S. C. Chen and G. S. Dhillon, "Interpreting Dimensions of Consumer Trust in E-Commerce," Information Technology and Management, vol. 4, no. 2, pp. 303-318, 2003/04/01 2003, doi: 10.1023/A:1022962631249.

[33] E. Delgado-Ballester and J. L. MunueraAlemán, "Does brand trust matter to brand equity?," Journal of Product \& Brand Management, vol. 14, no. 3, pp. 187-196, 2005, doi: 10.1108/10610420510601058.

[34] D. Ball, P. S. Coelho, and A. Machás, "The role of communication and trust in explaining customer loyalty: An extension to the ECSI model," European Journal of Marketing, vol. 38, no. 9/10, pp. 1272-1293, 2004, doi: 10.1108/03090560410548979. [35] S. L. Jarvenpaa, N. Tractinsky, and L. Saarinen, "Consumer Trust in an Internet Store: a Cross-Cultural Validation," Journal of ComputerMediated Communication, vol. 5, no. 2, 1999, doi: 10.1111/j.1083-6101.1999.tb00337.x.

[36] S. Hegner, Die Relevanz des Vertrauens für das identitätsbasierte Management globaler Marken (Dissertation). Bremen: Universität Bremen, 2012.

[37] H. D. McKnight, V. Choudhury, and C. Kacmar, "The impact of initial consumer trust on intentions to transact with a web site: a trust building model," The Journal of Strategic Information Systems, vol. 11, no. 3, pp. 297-323, 2002.

[38] E. W. K. See-To and K. K. W. Ho, "Value cocreation and purchase intention in social network sites: The role of electronic Word-of-Mouth and trust - A theoretical analysis," Computers in Human Behavior, vol. 31, pp. 182-189, 2014, doi: 10.1016/j.chb.2013.10.013.
[39] T. Oliveira, M. Alhinho, P. Rita, and G. Dhillon, "Modelling and testing consumer trust dimensions in e-commerce," Computers in Human Behavior, vol. 71, pp. 153-164, 2017/06/01/ 2017, doi: 10.1016/j.chb.2017.01.050.

[40] E. Botha and M. Reyneke, "The Influence of Social Presence on Online Purchase Intention: An Experiment with Different Product Types," Cham, 2016: Springer International Publishing, in Looking Forward, Looking Back: Drawing on the Past to Shape the Future of Marketing, pp. 180-183.

[41] Y. Kim and R. A. Peterson, "A Meta-analysis of Online Trust Relationships in E-commerce," Journal of Interactive Marketing, vol. 38, pp. 44-54, 2017/05/01/ 2017, doi: https://doi.org/10.1016/j.intmar.2017.01.001.

[42] A. Chaudhuri and M. B. Holbrook, "The chain of effects from brand trust and brand affect to brand performance: the role of brand loyalty," Journal of Marketing, vol. 65, no. April, pp. 81-93, 2001.

[43] J. Martin, G. Mortimer, and L. Andrews, "Reexamining online customer experience to include purchase frequency and perceived risk," Journal of Retailing and Consumer Services, vol. 25, pp. 81-95, 2015/07/01/ 2015, doi: 10.1016/j.jretconser.2015.03.008.

[44] O. K. Hussain, E. Chang, F. K. Hussain, and T. S. Dillon, "Determining the Failure Level for Risk Analysis in an e-Commerce Interaction," in Advances in Web Semantics I: Ontologies, Web Services and Applied Semantic Web, T. S. Dillon, E. Chang, R. Meersman, and K. Sycara Eds. Berlin, Heidelberg: Springer Berlin Heidelberg, 2009, pp. 290-323.

[45] S. Forsythe, C. Liu, D. Shannon, and L. C. Gardner, "Development of a scale to measure the perceived benefits and risks of online shopping," Journal of Interactive Marketing, vol. 20, no. 2, pp. 55-75, 2006/01/01/ 2006, doi: 10.1002/dir.20061.

[46] S. M. Forsythe and B. Shi, "Consumer patronage and risk perceptions in Internet shopping," Journal of Business Research, vol. 56, no. 11, pp. 867$875, \quad 2003 / 11 / 01 / 2003$, doi: 10.1016/S01482963(01)00273-9.

[47] D. Grewal, J. L. Munger, G. R. Iyer, and M. Levy, "The influence of internet-retailing factors on price expectations," Psychology \& Marketing, vol. 20, no. 6, pp. 477-493, 2003, doi: 10.1002/mar.10083.

[48] A. Patanasiri and D. Krairit, "A Comparative Study of Consumers' Purchase Intention on Different Internet Platforms," Mobile Networks and Applications, vol. 24, no. 1, pp. 145-159, 2019/02/01 2019, doi: 10.1007/s11036-018-1139-3.

[49] M.-T. Hsieh and W.-C. Tsao, "Reducing perceived online shopping risk to enhance loyalty: a website quality perspective," Journal of Risk 
Research, vol. 17, no. 2, pp. 241-261, 2014/02/07 2014, doi: 10.1080/13669877.2013.794152.

[50] S. L. Jarvenpaa, N. Tractinsky, and M. Vitale, "Consumer trust in an Internet store," Information Technology and Management, vol. 1, no. 1, pp. 45-71, 2000/11/01 2000, doi: 10.1023/A:1019104520776.

[51] D. Belanche, L. V. Casaló, and M. Guinalíu, "Website usability, consumer satisfaction and the intention to use a website: The moderating effect of perceived risk," Journal of Retailing and Consumer Services, vol. 19, no. 1, pp. 124-132, 2012/01/01/ 2012, doi: 10.1016/j.jretconser.2011.11.001.

[52] T. Hilken, K. de Ruyter, M. Chylinski, D. Mahr, and D. I. Keeling, "Augmenting the eye of the beholder: exploring the strategic potential of augmented reality to enhance online service experiences," Journal of the Academy of Marketing Science, vol. 45, no. 6, pp. 884-905, 2017/11/01 2017, doi: 10.1007/s11747-017-0541-X.

[53] J. Kim and S. Forsythe, "Sensory enabling technology acceptance model (SE-TAM): A multiplegroup structural model comparison," Psychology \& Marketing, vol. 25, no. 9, pp. 901-922, 2008, doi: 10.1002/mar.20245.

[54] J. B. Kim, "An empirical study on consumer first purchase intention in online shopping: integrating initial trust and TAM," Electronic Commerce Research, vol. 12, no. 2, pp. 125-150, 2012/05/01 2012, doi: 10.1007/s10660-012-9089-5.

[55] C. Soo Yeon and C. Park, "Online shopping behavior model: A literature review and proposed model," in 2009 11th International Conference on Advanced Communication Technology, 15-18 Feb. 2009 2009, vol. 03, pp. 2276-2282.

[56] Y.-H. Li and J.-W. Huang, "Applying theory of perceived risk and technology acceptance model in the online shopping channel," World Academy of Science, Engineering and Technology, vol. 53, no. 1, pp. 919-925, 2009.

[57] C. Alves and J. Luís Reis, "The Intention to Use E-Commerce Using Augmented Reality - The Case of IKEA Place," Cham, 2020: Springer International Publishing, in Information Technology and Systems, pp. 114-123.

[58] A. Y.-L. Chong, "Mobile commerce usage activities: The roles of demographic and motivation variables," Technological Forecasting and Social Change, vol. 80, no. 7, pp. 1350-1359, 2013/09/01/ 2013, doi: 10.1016/j.techfore.2012.12.011.

[59] R. A. Pearson, W. D. Salisbury, A. W. Pearson, and D. W. Miller, "Perceived security and World Wide Web purchase intention," Industrial Management \& Data Systems, vol. 101, no. 4, pp. 165 177, 2001, doi: 10.1108/02635570110390071.
[60] H. H. Bauer, C.-M. Albrecht, M. M. Neumann, and T. E. Haber, "Enhancing Customer Trust in E-Commerce Through Web Portals," Cham, 2015: Springer International Publishing, in Revolution in Marketing: Market Driving Changes, pp. 57-61.

[61] T. Verhagen, C. Vonkeman, F. Feldberg, and P. Verhagen, "Present it like it is here: Creating local presence to improve online product experiences," Computers in Human Behavior, vol. 39, pp. 270-280, 2014/10/01/ 2014, doi: 10.1016/j.chb.2014.07.036.

[62] J. Hoewe, "Manipulation check," The International Encyclopedia of Communication Research Methods, pp. 1-5, 2017.

[63] G. Hutcheson and N. Sofroniou, The multivariate social scientist. London: Sage, 1999.

[64] J. F. Hair, R. E. Andersin, R. L. Tatham, and W. C. Black, Multivariate Data Analysis with Readings. New York, NY: Macmillan, 1992.

[65] J. F. Hair, Jr., R. E. Anderson, B. J. Babin, and W. C. Black, Multivariate data analysis : a global perspective, 7 th ed. ed. Upper Saddle River (N.J.) : Pearson education (in eng), 2010.

[66] C. L. Stamper and S. S. Masterson, "Insider or outsider? How employee perceptions of insider status affect their work behavior," Journal of Organizational Behavior: The International Journal of Industrial, Occupational and Organizational Psychology and Behavior, vol. 23, no. 8, pp. 875-894, 2002.

[67] P. Eckstein, Angewandte Statistik mit SPSS: praktische Einführung für Wirtschaftswissenschaftler. Wiesbaden: Gabler, 2004.

[68] N. Döring and J. Bortz, "Forschungsmethoden und evaluation," Wiesbaden: Springerverlag, 2016.

[69] A. Field, Discovering statistics using IBM SPSS statistics. sage, 2013.

[70] A. F. Hayes, Introduction to mediation, moderation, and conditional process analysis: $A$ regression-based approach (Introduction to mediation, moderation, and conditional process analysis: A regression-based approach.). New York, NY, US: Guilford Press, 2013, pp. xvii, 507-xvii, 507. [71] S. Ha and L. Stoel, "Consumer e-shopping acceptance: Antecedents in a technology acceptance model," Journal of Business Research, vol. 62, no. 5, pp. 565-571, 2009/05/01/ 2009, doi: 10.1016/j.jbusres.2008.06.016.

[72] H. Sun and P. Zhang, "An exploration of affect factors and their role in user technology acceptance: Mediation and causality," Journal of the American Society for Information Science and Technology, vol. 59, no. 8, pp. 1252-1263, 2008, doi: 10.1002/asi.20819. 